\title{
Market Movement, Earning Capacity and Asset Fluctuation in Taiwanese Stock Exchange
}

Teng Yuan Cheng*

\begin{abstract}
This study examines a simple theory in which investors with market movement behaviours to show the influence of market movement on the relation between earning capacities, returns, and return volatility, and then we examine the empirical evidences from our theory. It first illustrates how asset fluctuation may fluctuate more than the fundamental value when investors have market movement behaviours. The result of excess asset price volatility in relation to earning capacity is presented. Asset price volatility is also shown to be positively related with the degree of market movement and the variation in earning capacity. Then, we empirically examine the influence of market movement in the relation between earning capacity and stock returns, and between earning capacity volatility and return volatility. Our observation indicates that the empirical results support the theory of market movement.
\end{abstract}

Keywords: Market movement, Earning capacity, Asset fluctuation

School of Finance, Nanjing Audit University, No:86 Yushan West Road, Pukou, Nanjing City, China - 211815; tybrian@gmail.com 


\section{Introduction}

Market movement, as a particular form of bounded rationality, is referred to as a cognitive boundary of holding information in memory and learning capacity new information. It is widely acknowledged to affect human behaviours and may also influence investors' behaviours in financial markets on several aspects. First, individuals may easily forget the history in their memory. They may find it hard to use all information to form fully rational forecasts. Moreover, the capacity for data could be constrained by technology. Second, many investors may choose not to exploit full information to make predictions to either save on the cost of information gathering or just simplify the calculation. Finally, investors may not always be assumed to have complete understanding or knowledge of the fundamental structure. In many circumstances, there occur structural changes arisen either from macroeconomic or industrial environments, such as financial crises, technological changes, restructures, new managements, and others. Therefore, it might be appropriate for investors to ignore older records and exploit only the most recent part of the historical data.

The theories regarding market movement are studied in Simon (1956), Smith and Deely (1975), Dow (1991), and Piccione and Rubinstein (1997). These studies provide several game theoretical frameworks to analyze human behaviors. Other researches, such as Daniel, Hirshleifer and Subrahmanyam (1998), and De Long, Schleifer, Summers and Waldmann (1990), have developed theoretical models with finite periods based on different psychological biases. The theoretical part of this study proposes a simple infinite-period model in which investors have market movement behaviors to investigate a few of the features of the relation between market movement, earning capacity, and asset fluctuation. ${ }^{1}$

${ }^{1}$ As mentioned by Simon (1972), there is no clear agreement on how one model shows bounded rationality. Other related works on bounded rationality may be founded on the excellent survey of Conlisk (1996). This study does not attempt to provide a complete framework to include all 
The asset price volatility has been a concern of many academic researchers and regulators. The traditional present value model based on the assumption of rational expectation could not satisfactorily provide a full understanding of price volatility in financial markets. Shiller $(1981,1989)$ found evidence of excess price volatility that cannot be explained by the dividend information. De Bondt and Thaler (1985) observed the phenomenon of overreaction. This study uses a simple model to illustrate how asset fluctuation may deviate from the fundamental value. The intuition behind the model can be described as follows. When the investor has received positive information about the earning capacity (which are being paid as dividends), based on the market movement decision he will tend to overweigh the received recent data. Therefore, the investor may become too optimistic and, as a result, overvalue the asset. The reverse argument holds as well. Consequently, the asset price may reflect too much in relation to the observations of earning capacity. This result contributes to providing an alternative explanation for the anomaly of excess price volatility and overreaction in financial markets.

The second part of this article deals with directly testing our theory on the relation between market movement, earning capacity, and volatilities by means of empirical data, which to our knowledge has not been fully examined. We take advantage of the margin trading data available for Taiwanese stocks, with the turnover rate of margin trading being used as a proxy for market movement. The margin trading data include quarterly panel data on the Taiwan stock market over the Q1 1991 to Q3 2008 period. Domestic individual investors, who are considered to have more irrational behavior and less information, account for $83.63 \%$ of the total trading volume. The average turnover rate for all participators in the market is $201.84 \%$ during the sample period, which implies that most trading activities are short-term. Given the above-mentioned market characteristics, the Taiwanese market has become particularly suitable for studying the impact of market movement on stock market volatility. When $\mathrm{E} / \mathrm{P}$, book-to-market and size

features of bounded rationality. Instead, it focuses on the implications in financial economics regarding market movement behavior. 
effects are controlled, the empirical results show that market movement is positively related to abnormal returns, and has a positive effect on the relation between earning capacity $(\mathrm{E} / \mathrm{P}$ as well) and abnormal returns. They also indicate that market movement is positively related to excess return volatility. These results are consistent with our theoretical predictions. The rest of this article is organized as follows. Section II presents the basic model, illustrating the properties of the asset price in the case of single-period market movement. The formal theoretical results from our simple model are presented in Section III, while the empirical data and empirical models are described in Section IV. In section V, we examine the empirical evidence from our theoretical results and illustrate how market movement may affect the stock market returns and volatility. Conclusions are in the final section.

\section{The Model}

Consider a risky asset with infinite-horizon earning capacity $\{d(t)\}_{t=1}^{\infty}$, which are being paid to the stockholders totally as dividends. For simplicity, earning capacity $d(t)$ is assumed to follow an i.i.d. binomial process whose realizations are $d_{L}$ and $d_{H}$, with probabilities of $1-\pi$ and $\pi$, respectively; $d_{H}>d_{L}>0$. Investors are not assumed to have knowledge of $\pi$. Denote the constant discount rate as $r$. At each time period $t$, a risk-neutral representative investor $i$ uses his subjective judgment to value the asset by the present value model as

$$
\mathrm{E}_{t}^{i}\left\{\frac{d_{t+1}}{1+r}+\frac{d_{t+2}}{(1+r)^{2}}+\cdots+\frac{d_{t+s}}{(1+r)^{s}}+\cdots\right\},
$$

where $\mathrm{E}^{i}$ is the subjective expectation. Consider first the benchmark case of rational expectations equilibrium (REE). By the i.i.d. assumption, the constant REE price at time $t$ is obtained as

$$
p^{e}(t)=p^{e}=\frac{\bar{d}}{r}=\frac{1}{r} \cdot\left[(1-\pi) \cdot d_{L}+\pi \cdot d_{H}\right], \text { for all } t,
$$

where $\bar{d}$ is the mean of the earning capacity. This representation simply describes the fundamental value of the asset as the discount 
stream of future earning capacity based on REE. Now consider the environment in which the representative investor faces $m$-period market movement, where $m$ is exogenously given as a natural number. ${ }^{2}$ The investor is assumed to anticipate future earning capacity as an i.i.d. process. However, he does not have access to the true model and determines the subjective valuation of the asset based on previous $m$-period historical data. The assessment of investors can then be described as a simple assessment based on the frequency of observations. It provides unbiased estimators when only the previous $m$-period observations are used and the other earlier records are deleted. Given the most recent observations of earning capacity as $d(t), d(t-1), \cdots, d(t-m+1)$, the estimator of $\pi$ by the investor's subjective judgment shall be

$$
q^{m}[d(t), d(t-1), \cdots, d(t-m+1)]=\frac{\text { the number of } d_{t-j} \text { being } d_{H}}{m} .
$$

Note that as $m$ approaches infinite, that is, as the investor is allowed to observe and exploit long-enough data, the above estimation converges to the true value of $\pi$, as is the case of REE by the law of large numbers. In this setting, an analytical solution for asset valuation can be obtained based on the investor's subjective expectation, which can be calculated from (1) and (3). The investor's subjective asset valuation at time $t$ can be written as

$$
p^{m}(t \mid d(t), d(t-1), \cdots, d(t-m+1))=\frac{1}{r}\left[\left(1-q^{m}\right) \cdot d_{L}+q^{m} \cdot d_{H}\right],
$$

where $q^{m}$ is the subjective estimator as in (3). The following part first illustrates the case of single-period market movement. Suppose

2 It is possible to consider the cost of information gathering in our framework. Then there considers an optimal decision problem that regards the trade off between cost and benefit for receiving the amount of information as in Dow (1991). However, incorporating such generality only complicates the solution while the basic argument of excess volatility in this study shall not be affected, and in general, it cannot provide closed-form solutions. 
that $d_{t}=d_{L}$ is realized. From (3) it follows that $q^{1}\left(d_{L}\right)=0$. This reflects the fact that the investor may take into account observed low earning capacity to conduct an overly pessimistic assessment of future earning capacity, which leads to a low asset price level as $p^{1}\left(d_{L}\right)=d_{L} / r$. The reverse argument is true when $d_{t}=d_{H}$ : an overly optimistic belief $q^{1}\left(d_{H}\right)=1$ and a high asset price $p^{1}\left(d_{H}\right)=d_{H} / r$ are presented. This result suggests an interesting phenomenon in which asset fluctuation may be overpriced (greater than $p^{e}$ ) or underpriced (less than $p^{e}$ ). Such behaviour of the asset price is consistent with evidence of excess volatility and overreaction. In our framework, overpriced valuation occurs when the investor receives and reflects the positive information on earning capacity too much. On the other hand, the asset shall be underpriced when low earning capacity are recently observed. Now we compare the mean of the asset price with the REE. The expected value of the prices can be computed as

$$
\begin{aligned}
& \mathrm{E}\left(p^{1}\right)=\operatorname{Prob}\left(d(t-1)=d_{L}\right) \cdot p^{1}\left(d_{L}\right)+\operatorname{Prob}\left(d(t-1)=d_{H}\right) \cdot p^{1}\left(d_{H}\right) \\
& =\frac{1}{r}\left[(1-\pi) \cdot d_{L}+\pi \cdot d_{H}\right]=p^{e} .
\end{aligned}
$$

The above result suggests that the asset price in one-period market movement has the same mean value as in a REE. However, the asset price volatility can be very different from the corresponding REE price volatility. By further calculations it follows that

$$
\begin{aligned}
\mathrm{V}\left(p^{1}\right) & =\operatorname{Prob}\left(d(t-1)=d_{L}\right) \cdot\left(p^{1}\left(d_{L}\right)-p^{e}\right)^{2}+\operatorname{Prob}\left(d(t-1)=d_{H}\right) \cdot\left(p^{1}\left(d_{H}\right)-p^{e}\right)^{2} \\
& =\frac{1}{r^{2}} \pi(1-\pi)\left(d_{H}-d_{L}\right)^{2}>0 .
\end{aligned}
$$

For comparison on the volatility of earning capacity $d_{t}$, the asset price can be calculated to obtain

$$
\begin{aligned}
& \mathrm{V}\left(d_{t}\right)=(1-\pi) \cdot\left(d_{L}-\bar{d}\right)^{2}+\pi \cdot\left(d_{H}-\bar{d}\right)^{2} \\
& =\pi(1-\pi)\left(d_{H}-d_{L}\right)^{2} .
\end{aligned}
$$


It then follows that the ratio of the volatility of the asset price in one-period market movement to the volatility of earning capacity shall be

$$
\frac{\mathrm{V}\left(p^{1}\right)}{\mathrm{V}(d)}=\frac{1}{r^{2}}
$$

This result demonstrates that the volatility of asset price $p^{1}$ can be much greater than the volatility of $d(t)$. For example, if the interest rate $r$ is considered as $10 \%$, then the ratio will become 100 . All these properties are presented as formal results in the next section.

\section{The Influence of Market movement on Asset fluctuation}

Now consider the general framework with general $m$-period market movement. Consider $x_{k}^{m}$ as the event set such that the number of realization of $\left\{d_{t-j}\right\}_{j=1}^{m}$ as $d_{H}$ is $k$. Denote $\#\left(x_{k}^{m}\right)=k$ as the number of $d_{H}$. The first result demonstrates the relationship between earning capacity and asset fluctuation.

Proposition 1: The asset price with $m$-period market movement $p^{m}(t)$ at time $t$ is positively related to the recent earning capacity, that is,

$$
p^{m}(t)=\frac{1}{r}\left[d_{L}+\frac{\#\left(x_{k}^{m}\right)}{m}\left(d_{H}-d_{L}\right)\right] .
$$

Proof: Since $d_{t}$ follows an i.i.d. binomial process, the probability distribution function for $x_{k}$ shall be

$$
\operatorname{Prob}\left(\#\left(x_{k}^{m}\right)=k\right)=\frac{m !}{k !(m-k) !}(1-\pi)^{m-k} \pi^{k}, k=0,1, \cdots, m .
$$

The subjective estimator is $q^{m}\left(x_{k}^{m}\right)=k / m$ by (3). Then the asset price $p^{m}$ can be represented as

$$
p^{m}(t)=\frac{1}{r} \cdot\left[\left(1-q^{m}\left(x_{k}\right)\right) d_{L}+q^{m}\left(x_{k}\right) d_{H}=\frac{1}{r}\left[d_{L}+\frac{\#\left(x_{k}^{m}\right)}{m}\left(d_{H}-d_{L}\right)\right] .\right.
$$


The above proposition suggests that in this framework, when high earning capacity are observed, the subjective expectation based on market movement causes the asset price to increase to a high level. Then on subsequent periods, as new information arrives, the price may move down, with long-term mean value as REE. Such pattern of asset price also helps to explain the phenomenon of overreaction as in De Bondt and Thaler (1985). ${ }^{3}$ The next result demonstrates the mean of asset fluctuation as the same with REE; that is, the asset price shall fluctuate around the REE price $p^{e}$.

Proposition 2: The unconditional mean value of the asset price with $\mathrm{m}$ -period market movement $p^{m}$ is equal to the REE price for any natural number $m$, i.e.,

$$
E\left(p^{m}\right)=p^{e}, m=1,2, \cdots
$$

Proof: From (8) the mean value of the asset price $p^{m}$ can be represented as

$$
\mathrm{E}\left(p^{m}(t)\right)=E\left(\frac{1}{r}\left[d_{L}+\frac{\#\left(x_{k}^{m}(t)\right)}{m}\left(d_{H}-d_{L}\right)\right] .\right.
$$

Given that the mean value of $\#\left(x_{k}^{m}\right)$ is $m \pi$ (Ross, 2000), the following can be obtained:

$$
\mathrm{E}\left(p^{m}\right)=\frac{1}{r}\left[d_{L}+\frac{m \pi}{m}\left(d_{H}-d_{L}\right)\right]=\frac{1}{r}\left[(1-\pi) \cdot d_{L}+\pi \cdot d_{H}\right]=p^{e}
$$

The above result suggests that the long run average asset price shall reflect the fundamental valuation. However, the asset price can deviate largely from the REE in the short run. It may be overpriced or underpriced, depending on the most recent observations of

3 The aim of our model is to provide a simple but accomplices the goal of providing a particular behavioural economics type explanation for the puzzle of asset volatility in asset fluctuation. The influence of market movement on the association between earnings and asset fluctuation, and related empirical observations are concentrated. We do not intend to offer a general theory to cover several other types of behaviours economics. The detailed outline of existing related behavioural finance may be referred to Barberis, Shleifer, and Vishny (1998) and Barbeis and Thaler (2003). 
earning capacity. In the next proposition, the property of excess volatility is demonstrated.

Proposition 3: The unconditional price volatility with $m$-period market movement is greater than the REE price for any finite natural number $m$; $m=1,2, \cdots$.

$$
V\left(p^{m}\right)=\frac{\pi(1-\pi)}{m} \frac{\left(d_{H}-d_{L}\right)^{2}}{r^{2}} .
$$

Furthermore, the ratio of the volatility of the asset price to the volatility of the earning capacity is a decreasing function of $m$ and $r$, i.e.,

$$
\frac{\mathrm{V}\left(p^{m}\right)}{V(d)}=\frac{1}{m \cdot r^{2}} .
$$

Proof: From the probability distribution function of $x_{k}^{m}$ in (7) and given that the variance of $\#\left(x_{k}^{m}\right)$ is $m \pi(1-\pi)$ (Ross, 2000), it follows that

$$
\mathrm{V}\left(p^{m}\right)=\frac{1}{r^{2}} \mathrm{~V}\left(\#\left(x_{k}^{m}\right)\right) \frac{1}{m^{2}}\left(d_{H}-d_{L}\right)^{2}=\frac{\pi(1-\pi)}{m} \frac{1}{r^{2}}\left(d_{H}-d_{L}\right)^{2}
$$

Then equation (10) is easily followed by (6). The above result demonstrates that the excess asset price volatility is related to the earning capacity. It also demonstrates that the price volatility is positively related to the degree of market movement $m$ and the variation of the earning capacity. The degree of excess volatility is greater when the interest rate is lower and the degree of market movement is stronger ( $m$ is smaller). Note that when $m$ approaches infinite, $V\left(p^{m}\right)$ converges at zero, as in the benchmark case of REE price $p^{m}$, which has only one value. Our result helps to provide additional explanation for the phenomenon of excess volatility as in Shiller $(1981,1989)$ by demonstrating the association between market movement, earning capacity, and asset valuation. 


\section{Empirical Models and Data Description}

Our theory implies that with market movement, stock prices tend to overreact on earning capacity, and the stock price volatility is positively associated with the degree of market movement. To test our theoretical results, we examine the relation between market movement, earning capacity, and volatility using the empirical data observed in Taiwan.

To normalize the different price levels, we examine the quarterly return over the Q1 1991 to Q3 2008 period for 1373 listed companies in the Taiwan Stock Exchange. The data were collected from the TEJ database. As suggested by Oh, Kim and Kim (2006), we use panel data allow us to increase the scope of information. This is especially beneficial in research with limited data. ${ }^{4}$ We use quarterly data because earning capacity can only be observed quarterly. Besides, daily returns are widely found to be serially correlated. We believe quarterly stock returns and return volatility may reduce the factors of autocorrelation. Accordingly, we shall focus on investigating the relation between stock returns, earning capacity, and market movement by controlling $\mathrm{E} / \mathrm{P}$, book-to-market, and size effects in the same spirit as previous studies such as Fama and McBeth (1973), Banz (1981), and Fama and French (1992):

$$
\begin{aligned}
R_{i t}=a & +b_{1} \mathrm{E} / \mathrm{P}(+)_{i t}+b_{2} \mathrm{E} / \mathrm{P} \text { dummy }_{i t}+b_{3} \text { short-termism }_{i t} \\
& +b_{4} \text { size }_{i t}+b_{5} \ln (\mathrm{B} / \mathrm{M})_{i t}+b_{6} \mathrm{E} / \mathrm{P}(+)_{i t} \times \text { short-termism }_{i t} \\
& +b_{7} \mathrm{E} / \mathrm{P} \text { dummy }_{i t} \times \text { short-termism }_{i t}+\mathrm{e}_{i t},
\end{aligned}
$$

where $R_{i t}$ is the abnormal return for company $i$ at period $t$, computed from market models using the previous 250 daily returns; ${ }_{5} \mathrm{E} / \mathrm{P}(+)$ is the earning capacity capacity-to-price ratio for

${ }^{4}$ Oh, Kim and Kim (2006) use panel cointegration analyses to test the relationship between earnings per share and stock price level. Stock price is found to move in the same direction as the firm's fundamental values, but the magnitude of the changes is inconsistent.

${ }^{5}$ We adopt the market model to compute abnormal return by regress stock returns on the market returns. 
positive-earning capacity firms; $\mathrm{E} / \mathrm{P}$ dummy is the dummy variable for positive- and negative- earning capacity firms, which equals one when the firm has negative earning capacity and zero otherwise; size is the logarithm of market capitalization; $\mathrm{B} / \mathrm{M}$ is the book-to-market ratio; market movement is the turnover rate of margin trading being used as a proxy; and $e_{i t}$ is the residual error of the regression. For robustness, we show two other models in which $\mathrm{E} / \mathrm{P}(+)$ and the earning capacity dummy are replaced by earning capacity per share and $\mathrm{E} / \mathrm{P}$, respectively.

Since market movement cannot be observed directly from empirical data, we take advantage of the margin trading data available for Taiwanese stocks, with the turnover rate of margin trading being used as a proxy for market movement for several reasons. First, in the Taiwanese market, margin trades should be resold within 1 year; therefore, margin trading is more likely to be short-term. Second, margin trading is only allowed for domestic individual investors whose behaviour is expected to be more short-termist. Third, the interest rate on margin borrowing is much higher than the lending rate (normally by about $2 \%-4 \%$ ). The higher investment cost provides an incentive to engage more in short-term trading.

We also examine the relation between excess volatility and market movement with the following model:

abnormal volatility $_{i t}=a+b_{1}$ earnings volatility ${ }_{i t}+b_{2}$ short-termism $_{i t}$

$$
\begin{aligned}
& +b_{3} \text { size }_{i t}+b_{4} \text { earnings volatility } \\
& +e_{i t}
\end{aligned}
$$

where abnormal volatility $_{i t}$ is the excess volatility for company $i$ at period $t$, measured by $\sigma_{i t}^{2}-\beta_{i t}^{2} \sigma_{m t}^{2}$, in which $\sigma_{i t}^{2}$ is the return volatility computed from daily returns over the quarter, $\sigma_{m t}^{2}$ is the market return volatility, and $\beta_{i t}$ is the beta value estimated from the market models; earnings volatility is computed from the previous four quarters; and $\mathrm{e}_{\mathrm{it}}$ is the residual error of the regression. 
Table 1. Descriptive statistics

\begin{tabular}{|l|l|l|l|l|l|l|}
\hline \multicolumn{1}{|c|}{ Variables } & Mean & Median & $\begin{array}{c}\text { First } \\
\text { quartile }\end{array}$ & $\begin{array}{c}\text { Third } \\
\text { quartile }\end{array}$ & Std. Dev. & Observations \\
\hline Abnormal return (\%) & 0.408 & -1.807 & 16.9584 & -21.5438 & 39.734 & 52119 \\
\hline $\begin{array}{l}\text { Abnormal return } \\
\text { volatility }\left(\%^{2)}\right.\end{array}$ & 460.468 & 349.572 & 595.6573 & 186.9281 & 647.465 & 52002 \\
\hline Market movement & 0.243 & 0.129 & 0.3361 & 0.0340 & 0.304 & 41768 \\
\hline Earnings per share & 0.369 & 0.290 & 0.7000 & 0.0100 & 1.175 & 62382 \\
\hline E/P & -0.035 & 0.010 & 0.0214 & -0.0022 & 0.681 & 49649 \\
\hline E/P(+) & 0.016 & 0.010 & 0.0215 & 0.0000 & 0.071 & 50648 \\
\hline E/P dummy & 0.240 & 0.000 & 0.0000 & 0.0000 & 0.427 & 62382 \\
\hline Earnings volatility & 0.554 & 0.051 & 0.1662 & 0.0158 & 6.630 & 57295 \\
\hline Ln(B/M) & -0.374 & -0.370 & 0.1043 & -0.8450 & 0.715 & 51225 \\
\hline Size & 15.106 & 15.051 & 16.0290 & 14.0370 & 1.545 & 52306 \\
\hline
\end{tabular}

Table 1 presents the descriptive statistics. The average abnormal quarterly return is $0.408 \%$, very close to zero, but the average abnormal return volatility is as large as $460.5 \%$. The earnings volatility is also large, reflecting the dispersion of earnings performance. The difference in firm sizes is insignificant since most firms in Taiwan are small. The average E/P dummy is 0.24 , which implies that $24 \%$ of quarterly earnings are negative. Significant dispersion exists in the market movement variable.

\section{Empirical Results}

We report the panel data estimates from a random effects regression model with GLS eliminates. Table 2 shows the relation between earnings, market movement, and stock returns. Model 3 provides a benchmark case without market movement. It indicates positive $\mathrm{E} / \mathrm{P}$ effects consistent with most developed and developing 
Table 2. Earnings, market movement, and stock returns

\begin{tabular}{|c|c|c|c|c|c|c|}
\hline \multirow[b]{2}{*}{ Regressors } & \multirow[b]{2}{*}{ Model 1} & \multicolumn{4}{|c|}{ Dependent variable: Abnormal Return } & \multirow[b]{2}{*}{ Model 6} \\
\hline & & Model 2 & Model 3 & Model 4 & Model 5 & \\
\hline \multirow[t]{2}{*}{ Constant } & $-8.473 * *$ & $-7.966 * * *$ & $-3.833^{*}$ & $-7.219 * * *$ & $-8.959 * *$ & $-8.511 * * *$ \\
\hline & $(-35.40)$ & $(-3.66)$ & $(-1.95)$ & $(-3.24)$ & $(-4.05)$ & $(-3.80)$ \\
\hline \multirow[t]{2}{*}{ Earnings per share } & $4.484 * * *$ & $1.872 * * *$ & & & & \\
\hline & $(25.52)$ & $(6.74)$ & & & & \\
\hline \multirow[t]{2}{*}{$\mathrm{E} / \mathrm{P}(+)$} & & & $16.193 * * *$ & $27.672 * * *$ & & $28.213 * *$ \\
\hline & & & $(3.95)$ & $(4.72)$ & & $(4.62)$ \\
\hline \multirow[t]{2}{*}{ E/P dummy } & & & $-5.287 * * *$ & $-5.264 * * *$ & & $-3.427 * * *$ \\
\hline & & & $(-12.32)$ & $(-10.99)$ & & $(-5.80)$ \\
\hline \multirow[t]{2}{*}{$\mathrm{E} / \mathrm{P}$} & & & & & $7.122 * * *$ & \\
\hline & & & & & $(7.06)$ & \\
\hline \multirow[t]{2}{*}{ Market movement } & $31.037 * *$ & $24.030 * * *$ & & $24.950 * * *$ & $24.389 * *$ & $26.078 * *$ \\
\hline & $(51.18)$ & $(34.64)$ & & $(39.05)$ & $(37.51)$ & $(29.10)$ \\
\hline \multirow[t]{2}{*}{$\begin{array}{l}\text { Earnings per share } * \\
\text { Market movement }\end{array}$} & & $2.893 * * *$ & & & & \\
\hline & & $(4.42)$ & & & & \\
\hline \multirow[t]{2}{*}{$\mathrm{E} / \mathrm{P} *$ Market movement } & & & & & $67.122 * *$ & \\
\hline & & & & & $(9.22)$ & \\
\hline \multirow[t]{2}{*}{$\begin{array}{l}\mathrm{E} / \mathrm{P}(+) * \text { Market } \\
\text { movement }\end{array}$} & & & & & & 20.936 \\
\hline & & & & & & $(0.56)$ \\
\hline \multirow[t]{2}{*}{$\begin{array}{l}\text { E/P dummy* Market } \\
\text { movement }\end{array}$} & & & & & & $-8.173 * * *$ \\
\hline & & & & & & $(-4.86)$ \\
\hline \multirow[t]{2}{*}{$\mathrm{Ln}(\mathrm{B} / \mathrm{M})$} & & $-8.317 * * *$ & $-11.774 * *$ & $-8.645 * * *$ & $-9.009 * *$ & $-8.726 * * *$ \\
\hline & & $(-25.36)$ & $(-42.64)$ & $(-26.42)$ & $(-27.70)$ & $(-26.58)$ \\
\hline \multirow[t]{2}{*}{ Size } & & -0.066 & 0.078 & -0.027 & 0.036 & 0.028 \\
\hline & & $(-0.46)$ & $(0.60)$ & $(-0.18)$ & $(0.24)$ & $(0.19)$ \\
\hline Adjusted $\mathrm{R}^{2}$ & 0.077 & 0.093 & 0.057 & 0.093 & 0.093 & 0.094 \\
\hline Observations & 41569 & 41290 & 49679 & 40267 & 39388 & 40267 \\
\hline
\end{tabular}

markets. However, we find that negative $\mathrm{B} / \mathrm{M}$ effects exist, and size has no explanatory power for returns in the Taiwan market. Considering market movement in Model 4, significant market movement effects are found, leaving the properties of other factors unchanged. The results are robust when considering that $\mathrm{E} / \mathrm{P}(+)$ and the E/P dummy are replaced by either earnings per share in Model 1 or by E/P in Model 2. Models 5 and 6 show that market movement amplifies $\mathrm{E} / \mathrm{P}$ effects when the cross-variable $\mathrm{E} / \mathrm{P}^{*}$ market movement is incorporated.

Note: The numbers within parentheses are the t-statistics of corresponding coefficients. Stars refer to the level of significance: *, $10 \%$;**, 5\%; and ***, $1 \%$.

The association between market movement and return volatility is reported in Table 3 . The benchmark case without market movement 
is shown in Model 1, which indicates a positive relation between earnings volatility and return volatility. Market movement has a significant effect on return volatility in Models 2 and 3. Negative cross-variable effects are also observed in Models 4 and 5, partly because of a negative correlation (with a correlation coefficient of -0.33) between market movement and earnings volatility. As mentioned by Caner and Önder (2005), the asset market volatility in emerging markets may be associated with other risks, such as the exchange rate risk and lagged return. One interesting finding in their study shows that exchange rate volatility is not a significant factor for return volatility in the Taiwanese market. In our study, however, the use of quarterly data may preclude the daily autocorrelation between stock returns; we shall therefore focus on the role of market movement on the association between earnings and return volatility.

Table 3. Earnings volatility, market movement, and return volatility

\begin{tabular}{|c|c|c|c|c|c|}
\hline \multirow[b]{2}{*}{ Regressors } & \multirow[b]{2}{*}{ Model 1} & \multicolumn{3}{|c|}{$\begin{array}{l}\text { Dependent variable: abnormal return } \\
\text { volatility }\end{array}$} & \multirow[b]{2}{*}{ Model 5} \\
\hline & & Model 2 & Model 3 & Model 4 & \\
\hline \multirow[t]{2}{*}{ Constant } & $2152.641 * * *$ & $394.741 * * *$ & $2078.089 * * *$ & $1732.506 * * *$ & $2067.677 * * *$ \\
\hline & $(45.46)$ & $(79.05)$ & $(73.25)$ & $(61.05)$ & $(72.89)$ \\
\hline \multirow[t]{2}{*}{$\begin{array}{l}\text { Earnings } \\
\text { volatility }\end{array}$} & $7.889 * * *$ & & $9.275^{* * *}$ & $10.295 * * *$ & $11.429 * * *$ \\
\hline & $(14.10)$ & & $(26.82)$ & $(25.21)$ & $(28.85)$ \\
\hline \multirow[t]{2}{*}{$\begin{array}{l}\text { Market } \\
\text { movement }\end{array}$} & & $161.205 * * *$ & $262.100 * * *$ & & $268.729 * * *$ \\
\hline & & $(29.09)$ & $(48.35)$ & & $(49.34)$ \\
\hline \multirow[t]{2}{*}{$\begin{array}{l}\text { Earnings } \\
\text { volatility * } \\
\text { Market } \\
\text { movement }\end{array}$} & & & & $-10.530 * * *$ & $-20.396 * * *$ \\
\hline & & & & $(-5.58)$ & $(-11.10)$ \\
\hline \multirow[t]{2}{*}{ Size } & $-109.476 * * *$ & & $-113.325 * * *$ & $-86.470 * * *$ & $-112.673 * * *$ \\
\hline & $(-35.10)$ & & $(-60.36)$ & $(-46.61)$ & $(-60.03)$ \\
\hline Adjusted $\mathrm{R}^{2}$ & 0.039 & 0.043 & 0.140 & 0.093 & 0.142 \\
\hline Observations & 51244 & 41717 & 41312 & 41312 & 41312 \\
\hline
\end{tabular}

Note: The numbers within parentheses are the t-statistics of corresponding coefficients. Stars refer to the level of significance: *, $10 \%$;**, $5 \%$; and ${ }^{* * *}, 1 \%$. 
Table 4. Earnings volatility, market movement, and stock returns for different periods

\begin{tabular}{|l|l|l|l|l|}
\hline & \multicolumn{4}{|l|}{ Dependent variable: Abnormal Return } \\
\hline Regressors & $1991-1996$ & $1997-1998$ & $1999-2000$ & $2001-2008$ \\
\hline Constant & $103.468^{* * *}$ & $-34.118^{* * *}$ & $-38.474^{* * *}$ & $-14.348^{* * *}$ \\
\hline & $(-13.54)$ & $(-4.53)$ & $(-5.90)$ & $(-5.77)$ \\
\hline E/P(+) & $53.053^{* *}$ & $198.172^{* * *}$ & $45.817^{*}$ & $23.240^{* * *}$ \\
\hline & $(2.37)$ & $(2.96)$ & $(1.79)$ & $(3.68)$ \\
\hline E/P dummy & $-3.283^{*}$ & $-6.678^{* * *}$ & $-9.359^{* * *}$ & 0.589 \\
\hline & $(-1.71)$ & $(-3.69)$ & $(-6.27)$ & $(0.87)$ \\
\hline Market movement & $34.006^{* * *}$ & $20.855^{* * *}$ & $26.379^{* * *}$ & $37.924^{* * *}$ \\
\hline & $(20.95)$ & $(11.62)$ & $(11.15)$ & $(28.36)$ \\
\hline $\begin{array}{l}\text { E/P(+) }{ }^{*} \text { Market } \\
\text { movement }\end{array}$ & $-227.486^{* * *}$ & $-305.667^{* * *}$ & $-491.013^{* * *}$ & $-136.747^{* * *}$ \\
\hline & $(-2.81)$ & $(-2.82)$ & $(-4.48)$ & $(-2.81)$ \\
\hline $\begin{array}{l}\text { E/P dummy } \\
\text { Market movement }\end{array}$ & 0.857 & $-8.629^{* * *}$ & -0.599 & $-14.338^{* * *}$ \\
\hline & $(0.24)$ & $(-2.77)$ & $(-0.14)$ & $(-5.87)$ \\
\hline Ln(B/M) & $-12.541^{* * *}$ & $-18.682^{* * *}$ & $-15.836^{* * *}$ & $-8.665^{* * *}$ \\
\hline & $(-11.56)$ & $(-18.30)$ & $(-19.29)$ & $(-22.48)$ \\
\hline Size & $5.510^{* * *}$ & 0.543 & $1.227^{* * *}$ & $0.537^{* * *}$ \\
\hline & $(10.76)$ & $(1.17)$ & $(2.92)$ & $(3.30)$ \\
\hline Adjusted R ${ }^{2}$ & 0.165 & 0.245 & 0.191 & 0.094 \\
\hline observations & 5077 & 2860 & 4540 & 27990 \\
\hline
\end{tabular}

Note: The numbers within parentheses are the t-statistics of corresponding coefficients. Stars refer to the level of significance: * $10 \%$;*, $5 \%$; and ${ }^{* * *}$, $1 \%$.

To check whether the results are driven by extreme observations in some of the sub periods, in Tables 4 and 5 we subdivide the data into four sub periods: 1991-1996, 1997-1998, 1999-2000, and 2001-2008, and report the regression results on these four periods. The sub periods 1997-1998 and 1999-2000 are selected because of the Asian financial crises and internet bubble periods, respectively. The influences of market movement on returns are robust for all sub 
periods in Table 4. Cross-variable effects of market movement and $\mathrm{E} / \mathrm{P}(+)$ are also observed, while insignificant $\mathrm{E} / \mathrm{P}$ dummy*market movement is found in two sub periods, leading to an overall robust cross-variable effect between E/P and market movement on stock returns. Similarly, the associations between market movement, earnings volatility, and return volatility are shown with robustness in Table 5 .

Note: The numbers within parentheses are the $\mathrm{t}$-statistics of corresponding coefficients. Stars refer to the level of significance: *, $10 \%$;**, $5 \%$; and ${ }^{* * *}, 1 \%$.

Table 5. Earnings volatility, market movement, and return volatility for different periods

\begin{tabular}{|l|l|l|l|l|}
\hline & \multicolumn{4}{|l|}{ Dependent variable: Abnormal return volatility } \\
\hline Regressors & $1991-1996$ & $1997-1998$ & $1999-2000$ & $2001-2008$ \\
\hline Constant & $366.380 * * *$ & $702.915^{* * *}$ & $1549.365^{* * *}$ & $1713.548 * * *$ \\
\hline & $(7.49)$ & $(10.13)$ & $(20.99)$ & $(45.03)$ \\
\hline Earnings volatility & $2.675^{* * *}$ & $5.604^{* * *}$ & $12.988^{* * * *}$ & $16.603 * * *$ \\
\hline & $(6.99)$ & $(5.32)$ & $(10.86)$ & $(28.39)$ \\
\hline Market movement & $180.312^{* * *}$ & $263.366^{* * *}$ & $379.840 * * *$ & $479.800 * * *$ \\
\hline & $(29.16)$ & $(28.65)$ & $(20.30)$ & $(62.73)$ \\
\hline $\begin{array}{l}\text { Earnings volatility * } \\
\text { Market movement }\end{array}$ & -1.168 & $-7.328^{* *}$ & $-18.246^{* * *}$ & $-30.762^{* * *}$ \\
\hline & $(-0.56)$ & $(-2.30)$ & $(-4.75)$ & $(-8.40)$ \\
\hline Size & $-15.078^{* * *}$ & $-29.310^{* * *}$ & $-71.959 * * *$ & $-90.212 * * *$ \\
\hline & $(-4.95)$ & $(-6.91)$ & $(-14.84)$ & $(-35.57)$ \\
\hline Adjusted $\mathrm{R}^{2}$ & 0.181 & 0.238 & 0.130 & 0.171 \\
\hline observations & 5162 & 2904 & 4699 & 28547 \\
\hline
\end{tabular}

Note: The numbers within parentheses are the t-statistics of corresponding coefficients. Stars refer to the level of significance: *, $10 \%$; **, $5 \%$; and ***, $1 \%$.

\section{Conclusion}

This study documents a simple but clear model for studying the investor's decision that takes into account the cognitive limitation known as market movement. Considering market movement leads the investor to participate in the market with either optimistic or pessimistic expectations. The asset price volatility is shown to be 
much greater than the rational expectations equilibrium, while the mean value of the asset price stays the same as the rational expectations equilibrium. This framework demonstrates that excess asset price volatility is related to earnings, since investors overweigh the recent observations of earnings. A positive association between asset price volatility and market movement is also shown.

Besides the theory, our empirical results also contribute to providing a direct behavioural explanation for the cross-sectional differences in stock returns. The use of quarterly data allows us to describe the influence of market movement and earnings on stock returns and return volatility rather than considering the serial correlations that are necessary when daily data are used. By controlling the market risk (betas), size, book-to-market ratio, and earnings/price, this study provides new empirical evidence on the earnings-returns relationships in the Taiwanese market. Market movement is observed to amplify the effect of earnings on stock returns, and the results indicate significant positive influences of market movement on stock returns and return volatilities as well, which are generally consistent with our theory.

\section{Reference}

Banz, R. (1981). The relationship between return and market value of common stocks. Journal of Financial Economics. 9, 3-18.

Barberis, N., Shleifer, N., \& Vishny, R. (1998). A model of investor sentiment. Journal of Financial Economics. 49, 307-343.

Barberis, N., \& Thaler, R. (2003). A survey of behavioral finance. Handbook of the Economics of Finance. North Holland: Elsevier.

Caner, S., \& Önder, Z. (2005). Sources of volatility in stock returns in emerging markets. Applied Economics, 37, 929-941.

Conlisk, J. (1996). Why bounded rationality? Journal of Economic Literature, $34,669-700$.

Daniel, K. D., Hirshleifer, D., \& Subrahmanyam, A. (1998). Investor psychology and security market under- and overreactions. Journal of Finance, 53, 1839-86.

DeBondt, W., \& Thaler, R. H. (1985). Does the stock market overreact? Journal of Finance, 40, 793-808. 
De Long, J. B., Schleifer, A., Summers, L., \& Waldmann, R. (1990). Positive feedback investment strategies and destabilizing rational speculation. Journal of Finance. 45, 379-95.

Dow, J. (1991). Search decisions with limited memory. Review of Economic Studies, 58, 1-14.

Fama, E. F., \& French, K. R. (1992). The cross-section of expected stock returns. Journal of Finance, 47, 427-465.

Fama, E. F., \& McBeth, J. D. (1973). Risk, return, and equilibrium: Empirical tests. Journal of Political Economics, 3, 607-636.

Froot, K. A., Scharf, D. S., \& Stein, J. C. (1992). Herd on the street: informational inefficiencies in a market with short-term speculation. Journal of Finance. 47, 1461-1484.

Oh, K. Y., Kim, B., \& Kim, H. (2006). An empirical study of the relation between stock price and EPS in panel data: Korea case. Applied Economics. 38, 2361-2369.

Piccione, M., \& Rubinstein, A. (1997). On the interpretation of decision problems with imperfect recall. Games and Economic Behaviour, 20, 3-24.

Ross, S. M. (2000). Introduction to probability models (7th ed.). San Diego: Academic Press.

Simon, H. A. (1956). Rational choice and the structure of the environment. Psychological Review, 63, 129-38.

Simon, H. A. (1972). Theories of bounded rationality. In C. B. McGuire, \& R. Radner (Eds.), Decision and organization. North-Holland Publishing, London.

Smith, M. H., \& Deely, J. J. (1975). A secretary problem with finite memory. Journal of American Statistical Association. 70, 357-61.

Shiller, R. J. (1981). Do stock prices move too much to be justified by subsequent changes in dividends. American Economic Review, 71, 421-36.

Shiller, R. J. (1989). Market Volatility. Cambridge, MA: MIT Press.

Stein, J. C. (1989). Efficient capital markets, inefficient firms: A model of myopic corporate behaviour. Quarterly Journal of Economics, 104, 655-669. 